\title{
Using Skills-Based Emotional Intelligence Training to Improve Team Perfor- mance in Construction Management Programs
}

\section{Joshua Jason Mischung, Arizona State University}

Graduate student researching the impact of emotional intelligence in construction management programs and the construction industry.

\section{Mr. Jake Smithwick, Arizona State University}

Jake is a PhD student in the Del E. Webb School of Construction at Arizona State University. Jake's research studies the processes by which public institutions deliver their capital projects through best value procurement. He has assisted research sponsors execute best value projects since 2002 and is currently the lead project manager and researcher for the Minnesota and Northern Midwest Regional efforts. Jake has supervised the procurement and risk management of over 100 best value projects, totaling $\$ 421 \mathrm{M}$ in project value ( $\$ 357 \mathrm{M}$ of this in design, construction, and facilities management). The projects were delivered with various methods (Design-Bid-Build, Design-Build, and CM at Risk), diverse scopes and trades (retrofit, new construction, tenant improvements, general / mechanical / electrical / roofing construction), at a wide range of public owners (school districts, cities, counties, states, universities, and the largest federal government purchaser of goods \& services). In the past four years, Jake has given 74 presentations to over 2,200 people throughout the United States and Canada. Jake possesses a BS in Computer Information Systems and a MS in Construction Management. Jake is concurrently pursuing a $\mathrm{PhD}$ in Construction Management and a Master of Public Administration (MPA).

\section{Prof. Kenneth Timothy Sullivan, Arizona State University}

Dr. Anthony Perrenoud, University of Oklahoma

Dr. Anthony Perrenoud is an Assistant Professor at the University of Oklahoma in the Construction Science Division of the College of Architecture. His teaching and research interests are in the area of pre-construction services, risk management, MEP systems, and leadership. Anthony holds a Bachelor of Science, Master of Science, and a PhD in Construction Management, all from Arizona State University. Prior to joining OU, Perrenoud held several managerial positions in the electrical industry and provided consultation to several government organizations on alternative project delivery methods. 


\section{Using Skills-Based Emotional Intelligence Training to Improve Team Performance in Construction Management Programs}

One of the most frequently requested skills of graduating Construction Management (CM) students is the ability to work well in team settings. As a result CM programs have incorporated many team activities and projects into their curriculum. This has provided students with exposure to the dynamics and complexities of working in team settings. But many CM programs stop at exposure. Examining another field's training practices suggests another crucial step in preparing students for the construction industry. Competitive sports teams operate in dynamic, complex, fast paced, high-pressure environments. All characteristics that are shared with today's construction environment. Much like CM programs competitive sports teams will often scrimmage to expose athletes to the environment they will be expected to perform in. Where CM programs can learn from these high performing teams is in the skills-based training leading up to the scrimmage. Just like the athletes, students will perform better when they are taught executable skills prior to being exposed to team environments than they would have without any upfront skills training.

Over the past decade a myriad of evidence has amassed linking higher levels of emotional intelligence to both individual and team performance. Organizations outside of the construction industry have taken notice and implemented efforts to increase awareness and training of emotional intelligence. As a result these organizations are enjoying higher levels of performance at both the individual and team level. Unfortunately the construction industry remains hesitant and slow to embrace emotional intelligence as an effective method of improving performance. Due to emotional intelligence's documented positive impact on individual and team performance, as well as the ability to improve emotional intelligence through training, it was chosen as the method used to train students in a large Construction Management undergraduate class to operate in team settings. Researchers collected project performance data for two semesters. The second semester a certified emotional intelligence (EI) trainer provided skills-based EI training to the students prior to beginning their final project. Students that received the skills-based EI training not only performed better on their final projects, but also reported better team communication.

\section{Introduction}

Similar to competitive sports teams, construction management teams operate in dynamic, complex, fast pace, and high-pressure environments. Over the past decade research has discovered the correlation between Emotional Intelligence (EI) and performance within the workplace, amongst teams, and in leadership situations. ${ }^{3,13,16}$ Construction Management (CM) students are often instructed on the importance of team work and leadership, but the authors have witnessed a lack of skills-based training related to EI at university CM programs. The authors believe that just like the athletes, CM students will perform better when they are taught executable skills prior to being exposed to team environments than they would have without any upfront skills training. 
The purpose of this paper was to determine if educating students in-depth on a small number of executable skills could positively impact their team performance. A skills-based EI study performed within a CM course at a large university in the United States assessed the impact that occurs when students are educated on executable EI skills related to working in teams. A semester project is performed by two groups of students, one group which receives education related to executable EI skills and one that does not. The EI skills education some of the students received demonstrated how they could be more self-aware to their emotional behaviors and how they can improve relationship management. The two hypotheses of the research are: 1) that the distribution of project scores would be higher for the group of students receiving the skills-based EI training, and 2) that the distribution of team evaluations would be higher for the group of students receiving skills-based EI training.

\section{Literature Review}

\section{Emotional Intelligence}

During the 1990s business managers began to discover a captivating method of assessing employees' potential performance that would be now known today as Emotional Intelligence (EI). Statements such as "EI may be the best predictor of life success" or "re-defining what it means to be smart" suggest that measures of personality can be powerful predictors of job performance and academic achievement. ${ }^{15}$ A large body of research began to grow on topics that covered emotions and its effect on quality of life and performance in the workplace. ${ }^{1,14}$

In a response to the new area of research, a variety of assessment tools have been developed in order to measure EI. To date the Mayer-Salovey-Caruso emotional intelligence test (MSCEIT) has become the most popular method of measuring EI. ${ }^{5}$ Mayer-Salovey-Caruso's basic definition of EI is "the ability to perceive and express emotion, assimilate emotion and thought, understand and reason with emotion, and regulate emotion in the self and others." 9 Mayer, Salovey, and Caruso's model consists of four branches; the ability to perceive emotions, the ability to use emotions to facilitate thought, the ability to understand emotions, and the ability to manage emotions. Although researchers have adopted and recommended the use of the MSCEIT $^{9}$, limitations with the measurement tool still exist. ${ }^{5}$ Even with the existing limitations that are present in research with EI, researchers have identified positive correlations with EI and performance.

Higher EI scores have been shown to improve performance within the workplace, amongst teams, and in leadership situations; all three of which are critical elements in the construction industry. Improved EI has been suggested to improve career performance due to the ability to handle stressful situations that exist in the workplace. ${ }^{13}$ EI is suggested to have a greater impact on team performance than individual performance, according to a leading researcher in the field. ${ }^{3}$ Teams with the ability to sense, understand, and react to teammate emotions demonstrate higher levels of EI. ${ }^{4}$ Often the team's norms and EI levels can be linked back to the leader's own EI. ${ }^{10}$ People skills are critical to a leader's success, particularly in projects, and can be linked to the leader's EI levels. ${ }^{16}$ 


\section{Emotional Intelligence in the Construction Environment}

Due to the nature of the high-stress construction environment, it has been suggested that EI should be more relevant and have a larger impact with the construction industry. ${ }^{3} \mathrm{~A}$ study in 2006 found that construction executives scored highest in stress tolerance, independence, and optimism; conversely they scored the lowest with interpersonal skills. ${ }^{2}$ Butler and Chinowsky contribute these executives' scores to difficult and demanding management situations that exist in construction. The lack of interpersonal skills found amongst construction executives persists as many observers and practitioners alike continue to describe the construction industry as dominated by aggressive, authoritative behavior where feelings of frustration and anger are accepted, and in many cases even rewarded. ${ }^{11,12,13}$ Similar to the industry, evidence has suggested that science and engineering students display more authoritative behavior than social science students.

A key aspect of EI research is the notion that it is "trainable", meaning that capabilities related to EI can be improved through education and exercises. ${ }^{3}$ Although research has identified that EI is a better predictor of capability in the professional settings, EI can also be contributed to academic performance. ${ }^{11}$ The previous research on EI and lack of research with EI within the construction management academics led the authors to conduct the following study.

\section{Method}

\section{Participants}

This study builds upon previous research efforts that analyzed the ability to improve the EI of college students through active, direct training on executable EI strategies. Participants in the study were students enrolled in a junior-level estimating course at a large university within the Unites States. Students in the estimating class were chosen as subjects for this study because of the final project at the end of the semester. The students voluntarily form teams of two to five, and perform a complete quantity takeoff, estimate and bid for an assigned construction project. The assigned construction project is a real project that has been constructed. The difficulty of the project and the firm deadline naturally produced stress and anxiety in many of the students, which allowed for both positive and problematic individual and team behaviors to be expressed.

Data was analyzed from 62 students, comprising of 18 project teams. Team size ranged from two students to five students with the following breakout; two teams of five students, eight teams of four students, four teams of three students, and four teams of two students. The median age of students was 22 years old, and 20 years old was the most common age. The participants were comprised of 84 percent males, and 16 percent females. The majority of students were in their junior year, and 67 percent were involved in at least one extracurricular activity. The average hours worked at an internship or job was 17.8 hours. The average industry experience was 3.4 years, and 1.1 years of estimating experience.

\section{Training}


Students in the training group received 90-minutes of skills-based EI training on two components of EI that the authors believed would be most beneficial to project performance; self-awareness and relationship management. Each component was introduced first at an awareness level, and then followed by an introduction to a usable conceptual tool and opportunity to practice using the tool with their team members during the training session. The context for the use of the conceptual tools presented focused on team interactions; specifically the kickoff meeting, planning, and managing project progress.

\section{Measures}

\section{Team Evaluation}

At the completion of the final project each student scored their team on the team's ability to communicate openly, honestly and effectively. To capture this information the authors adapted the Construction Industry Institute's Alignment Thermometer Tool to better reflect the context of a class project. $^{8}$ To score their team a 5-point Likert Scale was used, with 1 being the lowest score and 5 being the highest score. This data was used as the metric to measure students' opinions of their team experience.

\section{Project Performance}

The students' grades on the final project were used as the metric for team performance. The final project is creating a complete cost analysis and report for a real project that has been built within the last decade. A full set of drawings and specifications is given to them approximately 6 weeks before the end of the semester. The CSI Master Format is used in conjunction with RS Means for work structure breakout and pricing. Students are required to perform a full quantity takeoff of all CSI divisions and extend the cost for material, equipment, and labor using RS Means to provide a final cost to build. Afterwards all overhead, GSA costs, markup, and bonding are added. The requirements of the bid are a submission letter, a full cost breakout, and professional binding of all materials. The projects are graded 50 percent on the accuracy of the estimate, and 50 percent of the quality of the report. For the two semesters the mean project grade was 87 percent, with a standard deviation of 8 percent. The median project score for the two semesters was 88 percent.

\section{Results}

To determine if the 90-minute skills-based EI training had an impact Mann-Whitney U tests were run to determine if there were differences in project scores and project team experience between the control group, the group that did not receive the 90-minute skills-based EI training, and the group that did receive the training. The Mann-Whitney U test was chosen because several legitimate outliers existed in the data set. Outliers are a violation of an assumption for Independent-Samples T-test, and can have a large impact on the results of T-tests. Mann-Whitney U tests, on the other hand, are not affected by outliers while still measuring variance between to independent groups, making it the appropriate test for this data set. 
Distribution of project scores and responses to the team evaluation question assessing a project team's opinion of its communication were not similar for the control group and the training group, as assessed by visual inspection. Project scores for the training group (mean rank $=38.76$ ) were statistically significantly higher than for the control group (mean rank $=22.68$ ), $U$ $=723, z=3.530, p<.0005$. Responses to the team evaluation question measuring the team's opinion of its communication were also statistically significantly higher than for the control group. Table 1 displays the statistically significant results of the $\mathrm{U}$ tests.

Table 1

Significant Results of Mann-Whitney U Tests

\begin{tabular}{lcc}
\hline & Project Scores & Team Evaluation Responses \\
& $U=723, z=3.530, p<.0005$ & $U=541.5, z=2.119, p=.034$ \\
\hline Training Group & 38.76 & 33.41 \\
Control Group & 22.68 & 26.94
\end{tabular}

\section{Discussion}

The purpose of this research was to determine if training students with executable skills and tools to better work in teams would increase performance in student work groups. The hypotheses of this study were 1) that the distribution of project scores would be higher for the group of students receiving the skills-based EI training, and 2) that the distribution of team evaluations would be higher for the group of students receiving skills-based EI training. As shown in the results section the alternative hypotheses can both be accepted, and both null hypotheses rejected.

While the specific construction projects used for assignments and the team project were different for each semester, the curriculum itself was unchanged. Because of this it is reasonable to infer that the skills-based EI training that the second semester of students received had a positive impact on their ability to perform on team projects. What these findings suggest is that while giving students the opportunity to work together in groups can be helpful, further benefit is realized by first providing students with the necessary tools to effectively navigate group dynamics. The training students received covered very little of the EI construct itself, and instead primarily focused on just three statistically proven executable tools that students could use immediately to improve their performance.

Limitations do exist to the generalizability of these findings. A primary limitation is that only two semesters of data were collected. It is possible that the group of students is a higher performing group of students than the control group, and thus would have displayed higher performance even without receiving the EI tools training. It is also possible that the group of students that received the EI tools training have a naturally higher EI baseline. In which case one would expect higher performance in team environments from the group with higher EI. Further research will be conducted that will be able to take into account variations in class potential performance, as well as account for the impact of baseline EI in team performance

\section{Conclusion}


This paper presents a study on the impacts of team dynamics and performance with Construction Management (CM) students that have received additional education related to skills-based Emotional Intelligence (EI). The data presented significant findings of improved team work and project scores in groups of students that received additional training related to the application of EI, specifically, regarding self -awareness and relationship management. MannWhitney U tests found significant improvements with the students that received skills-based EI education compared to the students who did not receive the training. Significant improvements were also found in project team's assessment of their communication.

In conclusion, the study provides sufficient evidence that skills-based EI training improves team work amongst CM students. Understanding self-awareness and how emotions impact CM students' behavior allows them to better cope with stressful situations and ensure that individual emotions do not influence other team members. Furthermore, the construction industry highly relies on individual relationships, which makes relationship management a logical area of concentration in which CM students need before entering the industry. The authors strongly recommend that CM programs incorporate skills-based EI training into their curriculum to increase team performance amongst their students.

\section{References}

${ }^{1}$ Ashkanasy, N. M., Zerbe, W. J., \& Härtel, C. E. J. (2002). Managing Emotions in the Workplace. M.E. Sharpe.

${ }^{2}$ Butler, C., \& Chinowsky, P. (2006). Emotional Intelligence and Leadership Behavior in Construction Executives. Journal of Management in Engineering, 22(3), 119-125.

${ }^{3}$ Cherniss, C. (2010). Emotional Intelligence: Toward Clarification of a Concept. Industrial and Organizational Psychology, 3(2), 110-126.

${ }^{4}$ Chien, I. C., Seo, M.-G., \& Tesluk, P. E. (2012). Emotional intelligence, teamwork effectiveness, and job performance: The moderating role of job context. Journal of Applied Psychology, 97(4), 890-900.

${ }^{5}$ Côté, S. (2014). Emotional Intelligence in Organizations. Annual Review of Organizational Psychology and Organization Behavior, 1, 459-488.

${ }^{6}$ Frye, C. M., Bennett, R., \& Caldwell, S. (2006). Team Emotional Intelligence and Team Interpersonal Process Effectiveness. American Journal of Business, 21(1), 49-58.

${ }^{7}$ Gibbs, N. (1995, October 2). EMOTIONAL INTELLIGENCE: THE EQ FACTOR. Time, Cover story.

${ }^{8}$ IRR113-3. (2009, January 1). Alignment During Pre-Project Planning: A Key to Project Success, Version 2.1. Retrieved January 1, 2013, from https://www.construction-institute.org/scriptcontent/more/ir113_3_v2_more.cfm ${ }^{9}$ Jordan, P. J., Ashkanasy, N. M., Härtel, C. E. J., \& Hooper, G. S. (2002). Workgroup emotional intelligence: Scale development and relationship to team process effectiveness and goal focus. Human Resource Management Review, 12(2), 195-214.

${ }^{10}$ Koman, E. S., \& Wolff, S. B. (2008). Emotional intelligence competencies in the team and team leader: A multilevel examination of the impact of emotional intelligence on team performance. Journal of Management Development, 27(1), 55-75.

${ }^{11}$ Lindebaum, D., \& Cassell, C. (2012). A Contradiction in Terms? Making Sense of Emotional Intelligence in a Construction Management Environment. British Journal of Management, 23(1), 65-79.

${ }^{12}$ Lindebaum, D., \& Fielden, S. (2011). "It"s good to be angry': Enacting anger in construction project management to achieve perceived leader effectiveness. Human Relations, 64(3), 437-458.

${ }^{13}$ Love, P., Edwards, D., \& Wood, E. (2011). Loosening the Gordian knot: the role of emotional intelligence in construction. Engineering, Construction and Architectural Management, 18(1), 50-65.

${ }^{14}$ Mayer, J. D. (2002). Mayer-Salovey-Caruso Emotional Intelligence Test (MSCEIT): User's Manual. MultiHealth Systems. Inc., Toronto, Ontario.

${ }^{15}$ Newsome, S., Day, A. L., \& Catano, V. M. (2000). Assessing the predictive validity of emotional intelligence. Personality and Individual Differences, 29(6), 1005-1016. 
${ }^{16}$ Turner, R., \& Lloyd-Walker, B. (2008). Emotional intelligence (EI) capabilities training: can it develop EI in project teams? International Journal of Managing Projects in Business, 1(4), 512-534. 